\title{
Will more organs save more lives? Cost-effectiveness and the ethics of expanding organ procurement
}

\author{
Govind Persad (1D
}

Sturm College of Law, University of Denver

Correspondence

Govind Persad, Sturm College of Law, University of Denver, 2255 E. Evans Ave

Denver, Colorado 80208, USA

Email: gpersad@alumni.stanford.edu

\begin{abstract}
The assumption that procuring more organs will save more lives has inspired increasingly forceful calls to increase organ procurement. This project, in contrast, directly questions the premise that more organ transplantation means more lives saved. Its argument begins with the fact that resources are limited and medical procedures have opportunity costs. Because many other lifesaving interventions are more costeffective than transplantation and compete with transplantation for a limited budget, spending on organ transplantation consumes resources that could have been used to save a greater number of other lives. This argument has not yet been advanced in debates over expanded procurement and could buttress existing concerns about expanded procurement. To support this argument, I review existing empirical data on the cost-effectiveness of transplantation and compare them to data on interventions for other illnesses. These data should motivate utilitarians and others whose primary goal is maximizing population-wide health benefits to doubt the merits of expanding organ procurement. I then consider two major objections: one makes the case that transplant candidates have a special claim to medical resources, and the other challenges the use of cost-effectiveness to set priorities. I argue that there is no reason to conclude that transplant candidates' medical interests should receive special priority, and that giving some consideration to cost-effectiveness in priority setting requires neither sweeping changes to overall health priorities nor the adoption of any specific, controversial metric for assessing cost-effectiveness. Before searching for more organs, we should first ensure the provision of cost-effective care.
\end{abstract}

\section{KEYWORDS}

consequentialism, cost-effectiveness, John Taurek, opportunity cost, organ procurement, organ transplantation, resource allocation

\section{1 | INTRODUCTION}

Organ transplantation, like other medical innovations, offers the promise of saving lives. But, unlike drugs or devices whose provision is limited only by money, time, and natural resources, organ transplantation is limited by the supply of donated human organs. If only we had more organs-so the argument goes-we could save more lives. This article directly questions the premise that more organ transplantation means more lives saved. Its argument, grounded in the fact that resources are limited and medical procedures have opportunity costs, is simple. Although spending on organ transplantation saves the lives of patients with organ failure, it consumes resources that could have been used to save a greater number of other lives: those of patients with other illnesses who could have been saved using the resources we spend on transplants. Once these lives are added to the count, it is no longer clear that procuring more organs would save more lives overall.

Real-world proposals make this argument highly relevant. The assumption that procuring more organs will save more lives has inspired 
increasingly forceful calls to increase organ procurement. Janet Radcliffe Richards' recent book on the topic is titled "The Ethics of Transplants: Why Careless Thought Costs Lives." ${ }^{1}$ A recent defense of financial incentives for organ procurement contends that "saving lives is more important than abstract moral concerns." ${ }^{2}$ Antonia Cronin and John Harris argue that "[i]f we allow personal preference to take priority over the life-saving potential of organ transplants, we must take collective responsibility for the lives that will, as an inevitable consequence, needlessly be lost." ${ }^{3}$ Many other scholars have offered similar arguments. ${ }^{4}$ Policymakers have similarly framed increased procurement as a lifesaving choice: the health minister of Wales justified his country's shift to an opt-out organ procurement policy on the basis that "[o]rgan donation saves lives; increasing the rate of organ donation allows us to save more lives." Meanwhile, the developing world is beginning to consider which interventions should be subsidized as part of universal health coverage. ${ }^{6}$ Whether to devote limited health-care funding to organ transplantation thus merits close examination.

By challenging the premise that expanding procurement saves lives, ${ }^{7}$ this article also charts a novel direction in existing debates over organ procurement. Bioethicists who criticize proposals to expand organ procurement have uniformly conceded that procuring more organs would save more lives, and instead argued that specific proposals for expanded procurement are nevertheless ethically objectionable because of their risks to the welfare or autonomy of donors, their commodification of the human body, or their effects on third parties who do not wish to donate. ${ }^{8}$ The argument offered in this article-that procuring more organs will not save more lives overall-could reinforce these existing arguments, and vice versa.

Given that many non-transplantation interventions also have low cost-effectiveness and high opportunity costs, it is worth explaining this article's focus on transplantation. Beyond the simple limitations of space, there are two specific reasons for this focus. First, in contrast to debates about whether to provide other costly interventions such as

\footnotetext{
${ }^{1}$ Radcliffe, R. J. (2012). The ethics of transplants: Why careless thought costs lives. Oxford: Oxford University Press.

${ }^{2}$ Hippen, B. (2009). Saving lives is more important than abstract moral concerns: Financial incentives should be used to increase organ donation. Annals of Thoracic Surgery, 88(4),1053-1061.

${ }^{3}$ Cronin, A. J., \& Harris J. (2010). Authorisation, altruism and compulsion in the organ donation debate. Journal of Medical Ethics, 36(10), 627-631.

${ }^{4}$ Johnson, E. J., \& Goldstein, D. (2003). Do defaults save lives? Science, 302(5649), 1338-1340.

${ }^{5}$ Boyle, D. (2015). Organ donation: Groundbreaking law change in Wales means all adults become donors. The Telegraph,1 December. Retrieved from http://www.telegraph.co.uk/ news/nhs/12026298/Organ-donation-Groundbreaking-law-change-in-Wales-means-alladults-become-donors.htm

${ }^{6}$ Mock, C., Cherian, M., Juillard, C., Donkor, P., Bickler, S., Jamison, D. ... McQueen K. (2010). Developing priorities for addressing surgical conditions globally: furthering the link between surgery and public health policy. World Journal of Surgery, 34(3), 381-385.

${ }^{7}$ By "expanding procurement," I mean (as Richards and others do) procuring a larger quantity of organs, not procuring higher quality organs.

${ }^{8}$ Veatch, R. M., \& Ross, L. F. (2014). Transplantation ethics. Washington, DC: Georgetown
} University Press. new chemotherapies or hepatitis $C$ medications, ${ }^{9}$ the recent push for expanding organ procurement almost uniformly ignores the opportunity costs of transplantation. Second, while expanding access to other expensive interventions would merely require more money, many strategies for expanding organ procurement would not only require more money but also conflict with goals widely recognized as ethically important, such as securing explicit opt-in consent for medical procedures, avoiding financial pressure to sacrifice one's health, and not distributing life-saving treatments according to the recipient's ability to pay. (This second point also illustrates why this article's arguments need not support reducing organ procurement, rather than declining to expand it.)

\section{I THE OPPORTUNITY COSTS OF TRANSPLANTS: CONCEPTUAL AND EMPIRICAL CONCERNS}

Even when an organ transplant saves a life, it-like other medical interventions-has an opportunity cost. That is, it consumes resources that could have been used to provide medical care, including lifesaving care, to others. As Toby Ord has observed, providing one person a costly medical intervention can mean forgoing equally beneficial and less expensive interventions for thousands. ${ }^{10}$

The empirical data summarized in this section buttresses this conceptual argument by suggesting that the opportunity costs of transplantation (the medical benefits of other interventions that could be funded for the cost of a given transplant) are not merely conceptually possible but empirically substantial. Table 1 summarizes several reviews of the cost-effectiveness of transplantation, as well as low-cost medical interventions that target other illnesses.

The empirical data, while limited and variable, indicate that transplantation is far less cost-effective than many other interventions, including surgical ones. ${ }^{11}$ Many of these interventions-including those that counteract or prevent life-threatening diseases-are available but not universally provided, particularly in developing countries. In contrast, only one type of transplant-kidneys-is typically more cost-effective than $\$ 30,000 /$ quality-adjusted life year (QALY). Many, such as lung and liver transplants, can exceed $\$ 100,000 /$ QALY. A particularly striking example not included in the table is intestinal transplantation: one report indicates this costs $\$ 1,500,000$ per transplant, which means that an intestinal transplant patient would have to survive 15 years in perfect health for the transplant's cost-effectiveness to reach $\$ 100,000 / \mathrm{QALY}{ }^{12}$

\footnotetext{
${ }^{9}$ Bentley, C., Costa, S., Burgess, M. M., Regier, D., McTaggart-Cowan H., \& Peacock S. J. (2018). Trade-offs, fairness, and funding for cancer drugs: key findings from a deliberative public engagement event in British Columbia, Canada. BMC Health Services Research, 18(1), 339.

${ }^{10}$ Ord, T. (2013). The moral imperative toward cost-effectiveness in global health. Washington, DC: Center for Global Development. Retrieved from https://www.cgdev. org/sites/default/files/1427016_file_moral_imperative_cost_effectiveness.pdf

${ }^{11}$ Op. cit. note 6 .

${ }^{12}$ Bentley, T. S., Hanson, S. G. (2014). U.S. organ and tissue transplant cost estimates and discussion. Washington, DC: Milliman. Retrieved from www.milliman.com/uploadedFiles/insight/Research/health-rr/1938HDP_20141230.pdf
} 
TAB LE 1 Cost-Effectiveness of Organ Transplants and of Other Interventions

\begin{tabular}{|c|c|c|}
\hline Intervention & Cost-Effectiveness Ratio & Source \\
\hline Heart transplant & $\$ 45,000-76,000 / Q A L Y$ & Jarl and Gerdtham $(2011)^{14}$ \\
\hline Kidney transplant & $\begin{array}{l}\text { Cost saving (compared to } \\
\text { dialysis)-\$60,000/QALY; up to } \\
\$ 231,158 / \mathrm{QALY} \text { in oldest } \\
\text { patients }\end{array}$ & Jarl and Gerdtham (2011) \\
\hline Kidney transplant & $\$ 11,000 / Q A L Y$ & Jamison et al. (2006) \\
\hline Liver transplant & $\$ 31,000-106,788 / Q A L Y$ & Jarl and Gerdtham (2011) \\
\hline Lung transplant & $\$ 46,631-89,900 / Q A L Y$ & Jarl and Gerdtham (2011) \\
\hline Lung transplant & $\$ 238,200-464,000 /$ QALY & Jamison et al. (2006) \\
\hline $\begin{array}{l}\text { Heparin within } 48 \text { hours of onset of stroke or thrombo- } \\
\text { lytic therapy using recombinant tissue plasminogen } \\
\text { activator within } 3 \text { hours of onset }\end{array}$ & $\$ 1,278-2,675 / D A L Y$ & Jamison et al. (2006) \\
\hline Hip replacement & $\$ 5,223-6,893 / \mathrm{QALY}$ & Jamison et al. (2006) \\
\hline $\begin{array}{l}\text { Inhaled steroids for chronic obstructive pulmonary } \\
\text { disease }\end{array}$ & $\$ 7,800-13,400 / Q A L Y$ & Jamison et al. (2006) \\
\hline Metformin for prediabetes & $\$ 1,640-3,630 / \mathrm{QALY}$ & Jamison et al. (2006) \\
\hline Methadone for heroin dependence in high-HIV areas & $\$ 9,000 / \mathrm{QALY}$ & Jamison et al. (2006) \\
\hline One-visit VIA treatment for cervical cancer & $\$ 43-56 /$ life year & Jamison et al. (2006) \\
\hline Streptokinase for myocardial infarction & \$671/DALY & Jamison et al. (2006) \\
\hline
\end{tabular}

Data from Jarl and Gerdtham (2011) are in 2009 US\$; data from Kiberd and Larson (2000) are in 2000 US\$; data from Jamison et al. (2006) are in US\$, with varying dates.

DALY, disability-adjusted life year; QALY, quality-adjusted life-year; VIA, visual inspection with acetic acid.

Even though many health systems also incorporate factors other than cost-effectiveness when setting health-care priorities, these cost-effectiveness data indicate that the claim that transplantation saves lives is more dubious than is often portrayed. While money spent on transplants saves the lives of some patients with organ failure, it could have instead have been spent to save many more patients with other illnesses. Contrary to the rhetoric that organ donation is a "gift of life," a donated organ (unlike a monetary donation to a hospital) is a gift that has value only in the presence of other investments, including physicians' time, organ storage, hospital space, and immunosuppressive drugs. At a minimum, we need better data on the cost-effectiveness of transplantation before we expand its provision.

The above data also indicate that transplant procedures differ in cost-effectiveness. Kidney transplants can have a reasonably low cost per QALY and are generally cost-saving in comparison to dialysis, which many countries guarantee to patients with end-stage renal disease. ${ }^{13}$ In contrast, liver and lung transplants typically have a much higher cost per QALY, and do not replace a costlier treatment, as kidney transplant replaces dialysis. Ethical analyses of

\footnotetext{
${ }^{13}$ Barnieh, L., Gill, J. S.. Klarenbach, S., Manns, B. J. (2013). The cost-effectiveness of using payment to increase living donor kidneys for transplantation. Clinical Journal of the American Society of Nephrology, 8(12), 2165-2173.
}

transplantation should recognize these differences rather than treating organ transplantation as a monolithic intervention and calling for its expansion across the board.

Cost-effectiveness data are particularly relevant in unified, publicly funded health-care systems, where savings in one part of the health-care system are likely to be used to increase access to interventions elsewhere in the system. (Even if certain sectors of the health system have ring-fenced funding, funding can still be moved toward more cost-effective treatments within that sector, such as immune suppression drugs.) But opportunity costs can also be relevant even in health systems where some savings from reduced spending on transplantation are redirected to non-health goals. ${ }^{17}$ This can be true if the health gains from the non-redirected portion of health

\footnotetext{
${ }^{14}$ Jarl, J., \& Gerdtham, U. G. (2011) Economic evaluations of organ transplantations-a systematic literature review. Nordic Journal of Health Economics, 1(1), 61-82.

${ }^{15}$ Jamison, D. C., Breman, J. G., Measham, A. R., Claeson, G. A. M., Evans, D. B., Jha, P.... \& Musgrove, P. (2006). Disease control priorities in developing countries. (2nd ed.) New York: Oxford University Press.

${ }^{16}$ Kiberd, B. A., \& Larson, T. (2000). Estimating the benefits of solitary pancreas transplantation in nonuremic patients with type 1 diabetes mellitus: A theoretical analysis. Transplantation, 70(7),1121-1127.

${ }^{17}$ Daniels, N. (1986). Why saying no to patients in the United States is so hard: Cost containment, justice, and provider autonomy. New England Journal of Medicine, 314, 1380-1382.
} 
spending outweigh any health losses from reduced transplantation, or if the non-health goals are themselves morally compelling ones. While the opportunity costs of transplantation may already be recognized in clinical contexts (for instance, if other procedures are prioritized over transplantation when operating room space is scarce), it is valuable to recognize these costs at the macro-level as well as the micro-level.

The argument so far should be particularly compelling to those who argue for expanded transplantation on the basis that it has net population-wide benefits, including policymakers and consequentialist bioethicists. (I understand the claim that expanding procurement will save more lives as a claim that it will save more net lives-not merely as a claim that it will save the lives of those who receive transplants. A ban on ambulances would save the lives of those who are hit and killed by ambulances, but policymakers and consequentialist bioethicists would rightly find such a ban difficult to defend because it would cost the lives of many more people who could have been saved by prompt transport to a hospital.) The promise that transplantation will save lives and relieve suffering has understandably appealed to many consequentialists, while the non-consequentialist tenor of most arguments against transplantation, which focus on concerns like exploitation and consent, may repel them. Some consequentialists, notably Peter Singer and Julian Savulescu, have recently campaigned for expanded organ procurement without mention of transplantation's opportunity costs. ${ }^{18}$ I hope that a greater attention to opportunity costs may lead consequentialists, in particular, to be more cautious in their assessment of expanded organ procurement.

\section{3 | EVALUATING NON- CONSEQUENTIALIST DEFENSES OF EXPANDED PROCUREMENT}

Non-consequentialist advocates of expanded procurement might object to the argument above on the basis that transplantation should be compared only to other interventions that treat patients with organ failure. Transplantation is indeed frequently more costeffective than treatments like ventricular assist devices for heart failure or dialysis for kidney failure. But, in the absence of an argument for giving special priority to patients with organ failure, transplantation should be compared to a broad range of medical interventions rather than only with other interventions that treat organ failure. A non-consequentialist defense of expanding organ procurement must explain why the life of a patient with organ failure should count for more than the life of any other patient.

In this section I identify, evaluate, and rebut two major objections that might be advanced by those who value goals other than maximizing the population-wide benefits of health care. One makes the case that transplant candidates have a special claim to medical resources, while the other challenges the use of cost-effectiveness to set priorities.

\footnotetext{
${ }^{18}$ Savulescu, J., Singer, P., Isdale, W. (2015). We have a moral obligation to donate organs. Sydney Morning Herald 25 August. Retrieved from http://www.smh.com.au/comment/ australias-poor-organ-donation-rate-costing-lives-20150823-gj60ov.html
}

\subsection{The special claims of transplant candidates}

The opportunity cost argument may appear, at first blush, to mix apples and oranges. Treating heart attack victims, screening and treating cervical cancer, or vaccinating children against life-threatening diseases may save far more lives for a given sum of money than transplantation would. But transplantation is the best, and frequently only, treatment for organ failure. All the vaccines in the world are of no help to the patient with liver failure who will die unless she receives a transplant. Transplants should not be compared with the entire set of health-promoting interventions, but only with the set of other treatments for organ failure, which frequently has no other members.

In order for this objection to prevail, however, the objector must show not only that organ transplantation is the best treatment for organ failure but that patients with organ failure deserve priority over those with other conditions. Even if liver transplants are the best way to treat liver failure, the resources used to perform them could have saved many more patients with other illnesses. Expanding organ procurement therefore presents the same question as John Taurek's famous thought experiment:

The situation is that I have a supply of some life-saving drug. Six people will all certainly die if they are not treated with the drug. But one of the six requires all of the drug if he is to survive. Each of the other five requires only one-fifth of the drug. What ought I to do ${ }^{19}$

Taurek famously argued that we must give equal chances to the one person who requires all of the drug and to the five who require only one-fifth each. But most who have considered the example disagree: they believe we should save the five. ${ }^{20}$ Saving a patient with organ failure, like saving Taurek's patient who needs the entire supply of a scarce drug, consumes resources-here time and money, rather than portions of medicine-that could instead be used to save a greater number of others. Allowing the case for expanded procurement to depend on Taurek's widely rejected claim that society should be indifferent between saving more people and saving fewer would be an unacceptable concession for advocates for expanded procurement: it would make expanded procurement no more attractive than the ambulance ban discussed above.

A defense of expanded procurement that does not depend on Taurek's claim requires finding some basis for prioritizing transplant patients over others who might be saved instead. Accounts of priority-setting in medicine recognize a variety of ethically relevant considerations that can support saving fewer rather than more lives:

- Special obligations, such as professional duties. Some believe a

${ }^{19}$ Taurek, J. M. (1977). Should the numbers count? Philosophy and Public Affairs, 6(4), 293-316.

${ }^{20}$ Wasserman, D., \& Strudler, A. (2003). Can a nonconsequentialist count lives? Philosophy and Public Affairs, 31(1), 71-94; Parfit, D. (1978). Innumerate ethics. Philosophy and Public Affairs, 7(4), 285-301. 
physician should save her patient rather than a greater number of strangers.

- Differences in future benefit. Some believe we should save a few people who can live for many years, rather than many who can live for only a few years.

- Differences in past receipt of benefit. Some believe we should save a few people who have received less in the past, rather than many who have received more.

- Differences in past desert. Some believe we should save a few deserving people rather than many undeserving people.

- Temporal closeness of danger. Some argue that we should save a few individuals in imminent danger instead of saving more individuals in the future.

- Identifiability. Some argue that we should save a few identifiable individuals rather than many unidentified individuals.

None of these factors, however, justifies assigning greater importance to transplant recipients' interests than to others. There is no reason to think that prospective transplant recipients are owed more special obligations, are more deserving, have received less in the past, or can benefit more in future than other patients. In fact, prospective transplant recipients may have received more in the past and may be less able to benefit in the future than other patients, such as young children suffering from curable infectious diseases. ${ }^{21}$ Identifiability and the temporal closeness of danger favor transplantation over public health interventions, but not over treating cancer or heart attacks. Further, identifiability and temporal closeness are recognized as morally dubious criteria. ${ }^{22}$

A more sophisticated argument for saving transplant candidates rather than a greater number of other patients would appeal to group-based fairness. Taurek argues that a policy of always saving the greater number is least defensible when some group of individuals know in advance that they will not benefit from that policy. ${ }^{23}$ Declining to expand organ procurement may save more lives, but does so at the expense of declaring that a defined group of individuals, namely those with organ failure and diseases leading to organ failure, will be abandoned. This argument, however, should be unpersuasive, for four reasons:

- First, interventions other than organ procurement have the prospect of benefiting the group of individuals who are at risk of organ failure. As an example, vaccines against hepatitis could have benefited some of the individuals who now need a liver transplant. This reply may be especially persuasive to organizations who have disease-specific spending priorities. (A particularly striking example of this sort is the free or subsidized provision of cost-effective immunosuppressive medications for

\footnotetext{
${ }^{21}$ Sharp, D., Millum, J. (2015). Prioritarianism for global health investments: Identifying the worst off. Journal of Applied Philosophy, 35(1),112-132.

${ }^{22}$ Jecker, N. S. (2013). The problem with rescue medicine. Journal of Medical Philosophy, 38(1), 64-77.

${ }^{23}$ Op. cit. note 19
}

patients who have already received transplants. ${ }^{24}$ Even a narrow focus on helping patients with kidney failure would prioritize helping many patients who have already received transplants maintain their organs over helping a few to receive new organs.)

- Second, group-based fairness weighs both against and for expanding organ procurement. The opportunity costs of expanding organ procurement can lead to the abandonment of other, larger groups who need a cost-effective intervention that goes unfunded because of spending on transplantation.

- Third, declining to expand organ procurement does not entirely abandon the group of individuals with organ failure, but merely limits the amount of assistance they receive.

- Last, prospective transplant recipients are different from other groups, such as residents of rural areas or members of minority ethnic groups, because their primary commonality is their need for the intervention at issue. Organ failure, rather than being a socially visible or central part of someone's identity, is more naturally seen as simply one among many types of life-threatening bad medical fortune. ${ }^{25}$ That expanding organ procurement would help a group of people who all happen to have the same condition is not a reason to discount the equally important medical needs of many more people who lack a similar commonality.

Finally, if advocates for expanded procurement retreat to the more modest claim that expanding procurement protects organ recipients' life and health, rather than claiming that expanding procurement saves more lives overall, existing arguments against expanded procurement gain renewed force. Ethical concerns about consent, effects on third parties, exploitation, commodification, or organ donor autonomy raised by current critics of expanded procurement have much more purchase when they are not being weighed against a net loss of life. "Abstract moral concerns," such as consent and exploitation, count for more when we are not "saving more lives" by ignoring them.

\subsection{Challenging the relevance of cost- effectiveness}

The next set of objections I discuss challenge the claim that organ transplantation should be assigned lower priority than other, more cost-effective interventions. They make the case that setting priorities based on cost-effectiveness would require a complete overhaul of the health-care system; that cost-effectiveness is an ethically flawed metric; or that expanded procurement will make organ transplantation more cost-effective.

\footnotetext{
${ }^{24}$ Yen, E. F., Hardinger, K., Brennan, D. C., Woodward, R. S., Desai, N. M., Crippin, J. S. ... Schnitzler, M. A. (2004). Cost-effectiveness of extending Medicare coverage of immunosuppressive medications to the life of a kidney transplant. American Journal of Transplantation, 4(10), 1703-1708.

${ }^{25}$ Of course, systematically disadvantaged people are often more vulnerable to many illnesses that can lead to organ failure. But this would, at most, support giving special weight to saving systematically disadvantaged people, not giving special weight to performing organ transplants.
} 


\subsection{1 | Considering cost-effectiveness will require sweeping changes}

Introducing cost-effectiveness and opportunity costs into the ethical debate may seem to sweep far more broadly than organ transplantation. Setting spending priorities based strictly on cost-effectiveness may appear, for instance, to entail entirely abandoning clinical and surgical interventions in favor of population-level health interventions like vaccination as well as interventions outside the health system, such as environmental regulations, that target the social determinants of health.

One response to this observation is simply to acknowledge that organ transplantation is indeed only one among many cost-ineffective interventions that we provide. That we currently provide some interventions with poor cost-effectiveness is not a good argument for providing more of them. But a stronger response is also available: even if we consider factors other than cost-effectiveness there will almost always be interventions that are as good as transplantation with respect to these factors, while being much more cost-effective. Consider, for instance, an approach that sets priorities based on both an intervention's cost-effectiveness and its probability of saving people from impending death. Many of the interventions in Table 1 are as good as organ transplantation at saving people from impending death, and do so at a lower cost.

Alternatively, consider an approach that simply provides all treatments below a specified cost-per-QALY threshold, without regard to comparative cost-effectiveness. First of all, this approachwhile it might appear simple or politically appealing-is hugely wasteful. ${ }^{26}$ But, more importantly, while this approach might include some transplants, it would exclude others that are more expensive than the threshold. Additionally, as discussed above, many proposals for expanding organ procurement-such as presuming consent to medical procedures, changing the definition of death, or creating markets in body parts-conflict with recognized ethical values. In contrast, while providing expensive clinical or surgical interventions may be cost-ineffective, it does not conflict with any other important values.

\subsection{2 | Quality-adjusted life-years are a flawed metric}

Defenders of expanded organ procurement may also contend that the QALY is an ethically flawed basis for setting priorities in health care. ${ }^{27}$ I recognize the limitations of the QALY and have discussed them elsewhere. ${ }^{28}$ However, rejecting the use of QALYs in prioritysetting is a significant concession, because it makes the case for a

\footnotetext{
${ }^{28}$ Persad, G., Wertheimer, A., \& Emanuel, E. J. (2009). Principles for allocation of scarce medical interventions. Lancet, 373, 423-431.

${ }^{26}$ Op. cit. note 10 .

${ }^{27}$ Brock, D. W. (2003). Ethical issues in the use of cost-effectiveness analysis for the prioritization of health care resources. In T. T. T. Edejer, R. Baltussen, T. Adam, et al. (Eds.), WHO guide to cost-effectiveness analysis (pp. 289-312). Geneva: World Health Organization.
}

claim hitherto considered obvious-that expanded organ procurement would produce net medical benefits-dependent on the philosophically contested (and probably incorrect) proposition that QALYs should not be used in setting priorities. More importantly, other metrics for assessing cost-effectiveness, such as life-years or disability-adjusted life-years, judge transplantation no more favorably than the QALY does.

\subsection{3 | Transplantation will become more cost- effective}

Last, advocates might argue that expanding procurement will drive down the cost of transplantation, making it more cost-effective. However, this argument applies equally to the other interventions that compete with organ transplantation for scarce resources.

Furthermore, there is good reason to speculate that expanded procurement is likely to decrease, rather than increase, the average cost-effectiveness of transplantation. First, to the extent that the organs currently available are going to the individuals with the best prospect of benefit, additional transplants will go to patients who are older or otherwise have worse prognoses. Empirical studies have found that recipients' age and comorbidities dramatically worsen the cost-effectiveness of transplantation. ${ }^{29}$ Second, if the additional organs secured through expanded procurement are themselves of poorer quality, this could decrease cost-effectiveness substantially. ${ }^{30}$ Third, as advocates of financial incentives for donation concede, payments to donors represent an additional cost that must be factored into cost-effectiveness calculations.

\section{4 | CONCLUSION}

The assumption that increasing organ procurement will save more lives has hitherto gone unquestioned among both expanded procurement advocates and critics. This article challenges that assumption. More organs will save the lives of those who need organ transplants, but procuring and transplanting them will consume time and money that could have instead saved many more people who need other treatments.

When we compare the costs and benefits of transplantation to those of other interventions, rather than treating it as a sui generis gift of life, its virtues are less unique and the problems it presents are starker. If offered the opportunity to provide a new medical intervention that would cost upwards of $\$ 50,000$ per QALY and require departing from informed consent, changing the definition of death, or introducing markets in lifesaving medical care, many physicians, hospitals, and governments would reply "No thank you: we'll spend

\footnotetext{
${ }^{29}$ Jassal, S. V., Krahn, M. D., Naglie G., Zaltzman, J. S., Roscoe, J. M., Cole, E. H.... Redelmeier, D. A. (2003). Kidney transplantation in the elderly: A decision analysis. Journal of the American Society of Nephrology, 14(1), 187-196.

${ }^{30}$ Hilst, C. S., Ijtsma, A. J. C., Bottema, J. T., van Hoek, B., Dubbeld, J., Metselaar, H. J. ... Slooff, M. J. (2013). The price of donation after cardiac death in liver transplantation: A prospective cost-effectiveness study. Transplantation International, 26(4), 411-418.
} 
our money somewhere else." They would be right. Before we search for more organs, we should ensure the provision of cost-effective care.

\section{ACKNOWLEDGEMENTS}

Thanks to Carolyn Neuhaus, Sean Aas, Jennifer Blumenthal-Barby, Brendan Saloner, Daniel Sharp, Alastair Norcross, David Boonin, Eli Shupe, Vaughn Baltzly, Mario Macis, Scott Halpern, Zeke Emanuel, Toby Ord, Annette Rid, Alex Voorhoeve, Marion Danis, Debra Satz, and audiences at the University of Colorado Center for Values and Social Policy, the University of Colorado-Anschutz Center for Bioethics \& Humanities, the American Philosophical AssociationEastern Division, and the Department of Medical Ethics and Health Policy at the University of Pennsylvania.

\section{CONFLICT OF INTEREST}

None to declare.

\section{ORCID}

Govind Persad (iD https://orcid.org/0000-0002-9436-9209

\section{AUTHOR BIOGRAPHY}

Govind Persad is Assistant Professor at the University of Denver Sturm College of Law and is a 2018-2021 Greenwall Foundation Faculty Scholar in Bioethics. His research focuses on the legal and ethical dimensions of health insurance, health-care financing (both American and international), and markets in health-care services.

How to cite this article: Persad G. Will more organs save more lives? Cost-effectiveness and the ethics of expanding organ procurement. Bioethics. 2019;00:1-7. https://doi. org/10.1111/bioe.12587 